MATEC Web of Conferences 47. 04019 (2016)

DOI: $10.1051 /$ matecconf/20164704019

(C) Owned by the authors, published by EDP Sciences, 2016

\title{
A Review on Industrialised Building System Issues in Malaysia
}

\author{
Farah Deba Ayeop Abdul Khalii ${ }^{1, a}$, Farah Nora Aznieta Abd Aziz ${ }^{1}$, Salihuddin Hassim ${ }^{1}$ and Mohd Saleh \\ Jaafar $^{1}$ \\ ${ }^{1}$ Department of Civil Engineering, Faculty Engineering, Universiti Putra Malaysia, 43400 Serdang, Selangor \\ Malaysia
}

\begin{abstract}
Industrialised Building System (IBS) has been identified as a potential method to improve overall construction performance in term of quality, cost effectiveness, safety and health, waste reduction and productivity. There are several issues in managing IBS construction projects which lead to delays, poor qualities and cost overrun. This paper aims to analyze the issues in managing the construction phases of IBS projects. Based on this review, it shows that less effective use of IBS in Malaysia construction industry is due to unwillingness of the players to change from conventional system because they are not convinced with the IBS system. Therefore, appropriate bodies should help to increase the contractor's understanding and prepareness in using IBS system in the construction industry.
\end{abstract}

\section{Introduction}

An Industrialised Building System (IBS) is a construction system that is built using pre-fabricated components. The manufacturing of the components is systematically done using machine, formworks and other forms of mechanical equipment. The components are manufactured off-site and once completed will be delivered to construction sites for assembly and erection. IBS can be defined as a construction system which components are manufactured in a factory, on or off-site, positioned and assemble into structures with minimal additional site work [1]. The construction industry has started to embrace IBS as a method of realizing better construction quality and productivity, reducing risks related to occupational safety and health, alleviating issues for skilled workers and dependency on manual foreign labour, and achieving the ultimate goal of reducing the overall cost of construction. Apart from this, it offers minimal wastage, fewer site materials, a cleaner and neater environment, controlled quality, and lower total construction costs [2]. The experiences in some developed countries such as Japan, Germany and the United Kingdom indicate that there is a great potential for IBS to progress, as shown by their market share [3]. Among the most successful IBS implementations in the world are Sekisui Home (Japan), Living Solution (United Kingdom), Open House (Sweden) and Wenswonen (Netherlands) [4].

IBS consists of precast component systems, fabricated steel structures, innovative mould systems, modular block systems and prefabricated timber structures as construction components which mainly are parts of the building that are difficult and time consuming if cast on-site hence, are designed

\footnotetext{
${ }^{\text {a }}$ Corresponding author : faralaiqa@gmail.com
} 
detailed and cast as standardized components at the factory and transported to the site for assembly technologies [5]. According to Blismas [6] and CIDB [7], construction industry in developed countries has started to adapt IBS as a method of attaining better construction quality and productivity, reducing risks related to occupational safety and health, alleviating issues for skilled workers and dependency on manual foreign labor, and achieving the ultimate goal of reducing the overall cost of construction in order to minimal wastage, fewer site materials, a cleaner and neater environment, controlled quality and lower total construction costs [2]. On the same note, IBS adoption in Malaysia has long historical note since the 1960s to overcome shortage of houses such as Flat Pekeliling for Police Diraja Malaysia. However, the use of IBS was not sustained even though some of the international IBS systems were introduced in late 1960s and 1970s. It was found that those imported IBS systems were not compatible with Malaysia's climate and social practices resulting to closing down of precast concrete factories and continuing use of conventional system in the industry [8].

However, due to shortcoming of local skilled workers and overflow of unskilled workers from the neighboring countries, in 1999 country has recognised and enforcing use of IBS as one way of overcoming the problems. The IBS Strategic Plan was launched to promote IBS and followed by the IBS Roadmap 2003-2010 and IBS Roadmap 2011-2015, blueprints to industrialized construction by 2015 to chart and guide the awareness programmes, incentives, vendor scheme development, training, quality control and research and development programmes [9]. Since then, IBS is made compulsory in goverment building project with mimimum of $70 \%$ of the components should be made of IBS. However, implementation in private projects are non-traceble by the government and therefore the main problems are not solved althought the government already take initiative in using IBS system. Recently, enforcement of using IBS system are highlighted in the Economic Transformation Plan (ETP) particularlly to helps the country in managing a fast, better quality and environmental friendly construction methos in developing 'Greater Kuala Lumpur' in mega project such as Mass Rapid Transit (MRT), 1 Malaysia Financial District, Sungai Buloh and Sungai Besi mixed development project. The application of IBS in the construction industry plays an important role in supporting 12 National Key Economic Areas (NKEAs) in providing infrastructures and buildings. Therefore, the policies on IBS should be established in a sustainable manner to create high income society and economy and also creates more job opportunities. The potential usage of automation and robotic in IBS shall be explore by local industries so that the system becomes more effective and practical in the real application.

\section{IBS Construction Scenario}

Various attempts have been made to face the diverse challenges in the building sector by the government and related agency in the industry. The conventional construction method, which is commonly being practiced, is high cost and unable to respond to the huge demand in a short time with standard quality [10]. This traditional construction process has also been widely criticized for its fragmented approach to project delivery and its failure to form effective teams thus created a number of issues such as rework, time delay, rising cost, lack of communication and coordination, and wastages [10]. This traditional process which is segregated in nature are known as 'over the wall' syndrome, its breaking the project into a piece of smaller sub-project which is pass among different group in sequential manner throughout the entire project delivery and it contributed toward failure in forming effective teams [10].

In addition to that, the conventional construction method consists of a reinforced concrete frame and brick, beam, column, wall, and roof, which are cast in site using the timber framework while steel reinforcement is fabricated off-site. This method is labour intensive, involving formwork fabrication, steel bending and concreting. Thus, it requires many wet trades on-site, such as skill carpenters, plasterers, and brick workers. This process can be impeded and ruin by quality issues, unfavourable site conditions, a skilled labour shortage, bad weather conditions and material wastage [11]. The application of the conventional method to meet the huge demand of today with the certain quality 
standard, added up with the rising cost of labour and material will give a negative impact and hampered the development toward the construction industry.

According to Pan et al. [2], construction industry in developed countries has started to adapt IBS as a method of attaining better construction quality and productivity, reducing risks related to occupational safety and health, alleviating issues for skilled workers and dependency on manual foreign labour, and achieving the ultimate goal of reducing the overall cost of construction. It also had been highlighted as important use of technology and modern construction method in improving the efficiency of the implementation of construction projects [8]. According to CIDB [9], the use of IBS and innovation in the construction process also stimulated the growth of construction output and is seen as one of the most important sectors that contribute to the Gross Domestic Product (GDP) of a country. It is noted that the IBS can contribute significantly to fulfilling the demand and boosting it performance of construction industry.

Despite the change of policy, promotion and benefit that can be attain through the adoption of IBS construction industry, it is being hampered and still in its early stages. According to Hamid et al. [8] and Nawi et al. [10], although the IBS system improves the quality of projects, easier to control, reducing rectification work and lowering the total cost of construction, the trend of IBS usage in Malaysian construction projects are still below the national target. None the less, there are still limited numbers of contractors in Malaysia specialising in IBS that can undertake IBS jobs. Up until today, the IBS construction project still composed with the conventional construction method. Due to the combination of these two methods, IBS project can be assumed as multi-complex task and project [12] which will then contribute to other problems along the chain and the process of completing the project. This is agreed by several studies that opined that to reach the expertise in IBS, necessary knowledge and changes to organization process, practices, procedure and administration are required. Therefore it is clear that the IBS requires a shift in paradigm and a new set of management practise in undertaking the IBS project to its desirable outcome.

In addition toward the adoption and integration of IBS in the construction industry, it is revealed that the IBS supply chains are facing with the problem of fragmentation and adversarial relationships among players. It has been identified as the primary impediment toward the IBS construction project delivery. It should be noted that the construction process consists of five project management process which involved with various participants in a long duration that start with initiating, planning, executing, monitoring and closing phase [12]. The construction industry is unique compared to the other industries as it is a project oriented industry that produces unique projects [12] that are complex in nature thus, a proper and systematic management in needed. Management factors are domineering to ensure successful execution and determining the whole supply chain systems in IBS project [13].

The challenges and barriers in IBS implementation in Malaysia is basically due to the unwillingness of the players to convert from the conventional system of construction. The reasons for this could be due to lack of knowledge, unwilling to learn new things, comfortable and secure with current system and insufficient budget for mechanised system construction method [8]. Consequently, the awarded IBS projects are not well managed delayed and produced bad quality buildings [11]. Another possible reason for this bad reputation of IBS system is that manufacture of IBS components is involved only after the tender stage of the value chain. This lack of integration among relevant players in the design stage has resulted in a need for redesign and additional costs to be incurred if IBS is adopted [8].

\section{Summary}

Based on above discussion, it can be summarised that applying IBS system in Malaysia construction industry is still in unacceptable stage although it has been 16 years since it is introduced in 1999. The players, particularly privates companies are not convinced that IBS can contribute to significant cost savings, especially with the small volume of building constructed. Also, there is no guidance in terms of finance and cost control in IBS projects [14]. Therefore despite a need of a new approach of procurement using strategic partnering in the construction delivery system, support and professional 
training from government agencies such as CIDB and CREAM should be continue and proactively share the knowledge with the key players. This in turn perhaps will produce more IBS players and more coordinated and comprehensible guidelines in terms of applications, elements and cost control of IBS projects.

\section{References}

[1] CIDB, IBS Roadmap 2003-2010, Construction Industry Development Board Malaysia, Kuala Lumpur, (2003).

[2] W. Pan, A.G.F Gibb and A.R.J. Dainty, Strategies for integrating the use of offsite production technologies in housebuilding, Journal of Construction Engineering and Management, 138(11), 1331-1340, (2012).

[3] L.S. Peng and C.J. Chuan, a study of the readiness of precasters in just in time construction work study, International Journal of Productivity and Performance Management, 50(4), 131-140, (2001).

[4] M. Oostra and C. Claeson-Jonsson, Best Practices: Lesson Learnedon Building Concept in Open Building Manufacturing-Core Concept and Industrial Requirement, TNO Bouw, Delft, (2007)

[5] CIDB, Malaysian Construction Outlook 2007, Construction Industry Development Board Malaysia, Kuala Lumpur, (2007).

[6] N. Blismas and R. Wakefield, Drivers, constraints and the future of offsite manufacture in Australia, Construction Innovation, 9(1), 72-83, (2009).

[7] CIDB, IBS Roadmap 2003-2010, Construction Industry Development Board Malaysia, Kuala Lumpur, (2003).

[8] Z.A. Hamid, K.A.M. Kamar, M.Z.M. Zain, M.K. Ghani and A.H.A. Rahim, Industrialised building system (IBS) in Malaysia: The current state and R\&D initiatives, Malaysian Construction Research Journal, 2(1), 1-11, (2008).

[9] CIDB, The current state of industrialised building system (IBS) construction forward, Proceedings of the 1st IBS Roundtable Workshop, Kuala Lumpur, (2011).

[10]M.N.M. Nawi, A. Lee and K.M. Nor, Barriers to implementation of the industrialised building system ( IBS ) in Malaysia, The Built and Human Environment Review, 4, 22-35, (2011).

[11]E.C.W. Lou and K.A.M Kamar, Industrialized building systems: Strategic outlook for manufactured construction in Malaysia, Journal of Architectural Engineering, 18(2), 69-74, (2012).

[12]I.L. Jabar, F. Ismail, A.A. Mustafa, Issues in managing construction phase of IBS projects. Procedia - Social and Behavioral Sciences, 101, 81-89, (2013).

[13]F. Ismail, N.M. Yusuwan, H.E.A. Baharuddin, Management factors for successful IBS projects implementation, Procedia - Social and Behavioral Sciences, 68, 99-107, (2012).

[14]A.B.A. Rahman and W. Omar, Issues and challenges in the implementation of industrialised building systems in Malaysia, Proceedings of the 6th Asia-Pacific structural Engineering and Construction Conference, Kuala Lumpur, (2006). 